\title{
A Highly Selective and Sensitive Inorganic/Organic Hybrid Polymer Fluorescence "Turn-on" Chemosensory System for Iron Cations
}

\author{
Li-Juan Fan and Wayne E. Jones Jr. \\ Department of Chemistry, State University of New York at Binghamton, Binghamton, NY
}

\begin{abstract}
A polymer based fluorescence "turn-on" chemosensor is demonstrated with high sensitivity and selectivity towards $\mathrm{Fe}^{2+}$ cations. This system is an inorganic/organic hybrid system in which $\mathrm{Cu}^{2+}$ is coordinated at the receptor site of a conjugated polymer sensor. The unique quenching behavior of the $\mathrm{Cu}^{2+}$ towards this conjugated polymer was used to lower the initial fluorescence intensity of the sensory system. This results a highly sensitive and also selective sensory system towards $\mathrm{Fe}^{2+}$ as compared to other related divalent transition metal cations in solution.
\end{abstract}

The detection of metal ions in environmental or biological systems by fluorometric methods has gained tremendous attention in recent years. ${ }^{1}$ Fluorescence methods have several advantages over other techniques, including ease of detection, sensitivity and tunability. Numerous literature reports have appeared that explore fluorescence sensing of main group and transition metal ions, such as $\mathrm{K}^{+}, \mathrm{Hg}^{2+}, \mathrm{Cu}^{2+}, \mathrm{Cd}^{2+}, \mathrm{Zn}^{2+}$ and $\mathrm{Ag}^{+}$. Interestingly, relatively few examples have been reported as sensors for $\mathrm{Fe}^{2+}$ and $\mathrm{Fe}^{3+}$ cations. 3,4 Both $\mathrm{Fe}^{2+}$ and $\mathrm{Fe}^{3+}$ play vital roles in many biological processes and deficiencies or excesses of these ions are toxic or can lead to a variety of diseases. $3 \mathrm{c}, 5$ Though the human body can regulate iron to some extent, detection and analysis of bioactive iron represents an important healthcare challenge.

Most literature reports use fluorescence quenching as the readout mechanism for the sensor response. ${ }^{3}$ Very few involve a fluorescence "turn-on" response. ${ }^{4}$ Birck $e t$. al. recently published an elegant example involving small molecule sensors which selectively identified iron cations by amplified fluorescence. ${ }^{4 a}$ The greatest advantage of fluorescence "turn-on" sensors related to "turn-off" sensors is the ease of measuring low concentration contrast relative to a "dark" background. This reduces the likelihood of false positive signals and increases the sensitivity as demonstrated by numerous studies. ${ }^{6}$

In our previous work, poly[ $p$-(phenyleneethynylene)-alt-(thienyleneethynylene)] (PPETE) with a N, N, N'-trimethylethylenediamino receptor loaded on the thienylene ring (tmedaPPETE) was synthesized based on a strategy we advanced for a series of fluorescence "turnon" chemosensors. ${ }^{7}$ The fully characterized polymer was found to have a number average molecular weight of $3.67 \times 10^{4} \mathrm{~g} / \mathrm{mol}$ with a polydispersity of 2.73 . It showed varying fluorescence "turn-on" behavior in the presence of cations including $\mathrm{Li}^{+}, \mathrm{Na}^{+}, \mathrm{K}^{+}, \mathrm{Mg}^{2+}$, $\mathrm{Ca}^{2+}, \mathrm{H}^{+}, \mathrm{Mn}^{2+}, \mathrm{Fe}^{2+}, \mathrm{Co}^{2+}, \mathrm{Ni}^{2+}, \mathrm{Zn}^{2+}, \mathrm{Cd}^{2+}$, and $\mathrm{Hg}^{2+}$. The chelation-enhanced fluorescence (CHEF) mechanism has been described as involving coordination of the cation to a redox active amino receptor and subsequent termination of the photoinduced electron transfer (PET) 
quenching process with the fluorophore. ${ }^{1 \mathrm{a}, 1 \mathrm{~b}}$ While this mechanism was effective in our system the overall sensitivity was limited by a relatively high background fluorescence.

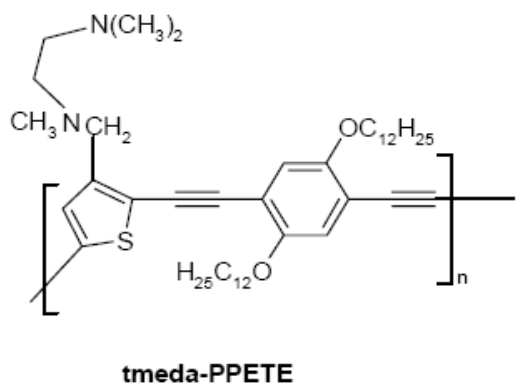

Interestingly, $\mathrm{Cu}^{2+}$ has been found to exhibit a noteworthy exception to the fluorescence enhancement behavior in this system. The fluorescence is significantly quenched with $\mathrm{Cu}^{2+}$ in solution as observed in typical PPETE chemosensors. ${ }^{8}$ Based on the $\mathrm{Cu}^{2+}$ quenching, we hypothesized that an inorganic/organic hybrid system may provide for both enhanced sensitivity and selectivity by preloading $\mathrm{Cu}^{2+}$ onto the amino receptor to totally quench the initial background fluorescence. Here we report the design and evaluation of a highly selective and sensitive fluorescence "turn-on" chemosensory system for iron cations based on a tmedaPPETE/ $\mathrm{Cu}^{2+}$ hybrid system.

The tmeda-PPETE/ $\mathrm{Cu}^{2+}$ hybrid system was prepared from THF solutions of tmeda-PPETE with a repeat unit concentration of $5 \mu \mathrm{M}$. CuCl 2 was added from aqueous stock solution to reach a final concentration of $5 \mu \mathrm{M}$ and to achieve a 1:1 ratio of $\mathrm{Cu}^{2+}$ to receptor. Consistent with previous studies, ${ }^{7,8}$ absorption peaks for the solution were observed around $440 \mathrm{~nm}$ and can be assigned to $\pi-\pi^{*}$ transitions from the conjugated polymer backbone. Thus, the solution was found to have no shift in the UV-Vis absorption. The emission intensity was quenched by more than $98 \%$ at $\lambda_{\max }=494 \mathrm{~nm}$ relative to the initial tmeda-PPETE polymer (see supporting information). This result is consistent with previous $\mathrm{Cu}^{2+}$ quenching results in the literature. ${ }^{9}$

The titration of $\mathrm{Fe}^{2+}$ was carried out by adding small aliquots of $\mathrm{FeCl}_{2}$ aqueous stock solution into the THF solutions containing the tmeda-PPETE/ $\mathrm{Cu}^{2+}$ hybrid system. We observed a greater than 100 fold enhancement in the fluorescence intensity upon titration of $10 \mu \mathrm{M}$ aqueous ferrous chloride (Figure 1). During the titration, the emission maximum did not shift and UVVis spectra showed negligible changes. This suggests no significant change in the overall electronic structure of the polymer upon addition of $\mathrm{Fe}^{2+}$. The final fluorescence intensity of the titrated solution was almost the same as for the titration of the pure polymer in the absence of $\mathrm{Cu}^{2+}$. Based on these results we assume that the $\mathrm{Fe}^{2+}$ has displaced the $\mathrm{Cu}^{2+}$ from the receptor. Attempts to directly observe the binding event by NMR and EPR have to date proved unsuccessful.

For comparison purposes, the influence of some other common divalent metal chlorides was investigated and the data is collected based on the relative change in fluorescence, $\mathrm{I} / \mathrm{I}_{0}$, in Figure 2. In each case, a total amount of $10 \mu \mathrm{M}$ of cations was added into the tmeda-PPETE/ $/ \mathrm{u}^{2+}$ solution. $\mathrm{Ca}^{2+}$ was selected as a representative alkali earth cation and $\mathrm{Hg}^{2+}, \mathrm{Zn}^{2+}, \mathrm{Ni}^{2+}$ and $\mathrm{Mn}^{2+}$ as divalent transition metal cations. To investigate the influence of solution acidity, addition of $\mathrm{HCl}$ aqueous solution into the sensory system was also carried out.

As shown in Figure 2, the system is highly selective for $\mathrm{Fe}^{2+}$ fluorescence enhancements of 150 fold. No other metal cations showed significant response, with the exception of $\mathrm{Hg}^{2+}$ with a 10 fold enhancement. The addition of all the cations into pure tmeda-PPETE THF solution is also shown for comparison. Results showed there was no significant difference in 
fluorescence enhancement among any of these cations for the pure chemosensor polymer. In all cases, the fluorescence enhancement was significantly smaller for the model compared to the tmeda-PPETE/ $/ \mathrm{Cu}^{2+}$ system. Thus, the high sensitivity and selectivity required the polymer/ $\mathrm{Cu}^{2+}$ hybrid.

While there was a 21 fold fluorescence enhancement in the presence of $\mathrm{H}^{+}$and iron or other aqueous cations can generate protons by hydrolysis, ${ }^{10}$ the change in fluorescence intensity for the metal cations is not a function of acidity alone. The hydrolysis pKa's provide insight into the relative acidities of the cation solutions. ${ }^{10,11}$, (supporting information) The acidity of $\mathrm{Fe}^{2+}$ in aqueous solution is very similar to $\mathrm{Zn}^{2+}$ and the $\mathrm{K}_{\mathrm{SP}}$ of their hydroxides is also very close. In addition, $\mathrm{HCl}$ and $\mathrm{HgCl}_{2}$ are much more acidic than the $\mathrm{FeCl}_{2}$ solution. However, $\mathrm{Zn}^{2+}, \mathrm{H}^{+}$and $\mathrm{Hg}^{2+}$ showed limited fluorescence enhancement in the system studied. Therefore, we conclude that the metal interaction with the polymer is required mechanistically.

The tmeda-PPETE/ $\mathrm{Cu}^{2+}$ system was highly selective toward $\mathrm{Fe}^{2+}$ cations in solution. Since this selectivity is not present for the parent tmeda-PPETE solutions, it must not be based simply on the association constant between the receptor ligand and the cation. It is likely that the selectivity is related to the relative ability of the cations to replace the $\mathrm{Cu}^{2+}$ already in coordination with the receptor. Competitive binding has previously been observed in small molecule sensors. ${ }^{13}$ The relative coordination of metal cations can often be related to their Lewis acid-base properties. However, $\mathrm{Fe}^{2+}$ and other cations do not follow a consistent trend so more work is necessary to specifically identify the mode of action for the selectivity.

In summary, a highly selective and sensitive sensory system towards iron cations in solution was achieved by preparing a transition metal derivatized conjugated polymer. By preloading $\mathrm{Cu}^{2+}$ onto the polymer receptor, fluorescence enhancements of over 2 orders of magnitude were achieved. This unique hybrid inorganic/organic polymer method may be useful in the detection of iron cations or modified for other analytes.

\section{Supplementary Material}

Refer to Web version on PubMed Central for supplementary material.

\section{Acknowledgements}

This research was funded by a grant from the National Institute of Health (NIH grant 1R15ES10106-01). The authors would also like to thank Dr. David C. Doetschman and Szu-Wei Yang for the EPR experiment and discussion, Dr. Stan Madan and Dr. Brendan Flynn for useful discussions.

\section{References and notes}

1. (a) Czarnik AW. Acc Chem Res 1994;27:302-308. (b) de Silva AP, Gunaratne HQN, Gunnlaugsson T, Huxley AJM, McCoy CP, Rademacher JT, Rice TE. Chem Rev 1997;97:1515-1566. [PubMed: 11851458] (c) Valeur B, Leray I. Coord Chem Rev 2000;205:3-40.

2. (a) Yang Y-K, Yook K-J, Tae J. J Am Chem Soc 2005;127:16760-16761. [PubMed: 16316202] (b) Yang RH, Chan WH, Li KA. J Am Chem Soc 2003;125:2884-2885. [PubMed: 12617649] (c) Taki M, Wolford JL, O'Halloran TV. J Am Chem Soc 2004;126:712-713. [PubMed: 14733534] (d) He H, Mortellaro MA, Leiner MJP, Fraatz RJ, Tusa JK. J Am Chem Soc 2003;125:1468-1469. [PubMed: 12568593] (e) Guo X, Qian X, Jia L. J Am Chem Soc 2004;126:2272-2273. [PubMed: 14982408] (f) Nolan EM, Lippard SJ. J Am Chem Soc 2003;125:14270-14271. [PubMed: 14624563] (g) Descalzo AB, Martínez-Máñez R, Radeglia R, Rurack K, Soto J. J Am Chem Soc 2003;125:3418-3419. [PubMed: 12643689]

3. (a) Espósito BP, Epsztejn S, Breuer W, Cabantchik ZI. Anal Biochem 2002;304:1-18. [PubMed: 11969183] (b) Ma Y, Luo W, Quinn PJ, Liu Z, Hider RC. J Med Chem 2004;47:6349-6362. [PubMed: 
15566304] (c) Weizman H, Ardon O, Mester B, Libman J, Dwir O, Hadar Y, Chen Y, Shanzer A. J Am Chem Soc 1996;118:12386-12375.

4. (a) Bricks JL, Kovalchuk A, Trieflinger C, Nofz M, Buschel M, Tolmachev AI, Daub J, Rurack K. J Am Chem Soc 2005;127:13522-13529. [PubMed: 16190715] (b) Ghosh P, Bharadwaj PK, Roy J, Ghosh S. J Am Chem Soc 1997;119:11903-11909.

5. Berne, RM.; Levy, MN. Physiology. 3. Mosby Year Book Inc; St Louis, Missouri: 1988. p. 705-706.

6. (a) McQuade DT, Hegedus AH, Swager TM. J Am Chem Soc 2000;122:12389. (b) Rurack K, Kollmannsberger M, Resch-Genger U, Daub J. J Am Chem Soc 2000;122:968-969.

7. Fan LJ, Zhang Y, Jones WE Jr. Macromolecules 2005;38:2844-2850.

8. (a) Zhang Y, Murphy CB, Jones WE. Macromolecules 2002;35:630-636. (b) Murphy CB, Zhang Y, Troxler T, Ferry V, Martin JJ, Jones WE Jr. J Phys Chem B 2004;108:1537-1543.

9. (a) Santis G, Fabbrizzi L, Licchelli M, Mangano C, Sacchi D. Inorg Chem 1995;34:3581-3582. (b) Bernhardt PV, Flanagan M, Riley MJ. Chem Soc Dalton Trans 1999;20:3579-3584. (c) Fabbrizzi L, Licchelli M, Pallavicini P. Acc Chem Res 1999;32:846-853.

10. Banes, CF.; Mesmer, RE. The Hydrolysis of Cations. Wiley-Interscience; New York: 1976.

11. Lide, DR. CRC Handbook of Chemistry and Physics. CRC Press LLC; Boca Raton, London, New York, Washington, D.C: 2002.

12. All the solutions were prepared immediately before titration and experiments were completed within 1 hour to minimize cation side reactions such as hydrolysis.

13. Wiskur SL, Ait-Haddou H, Lavigne JJ, Anslyn EV. Acc Chem Res 2001;34:963-972. [PubMed: 11747414] 


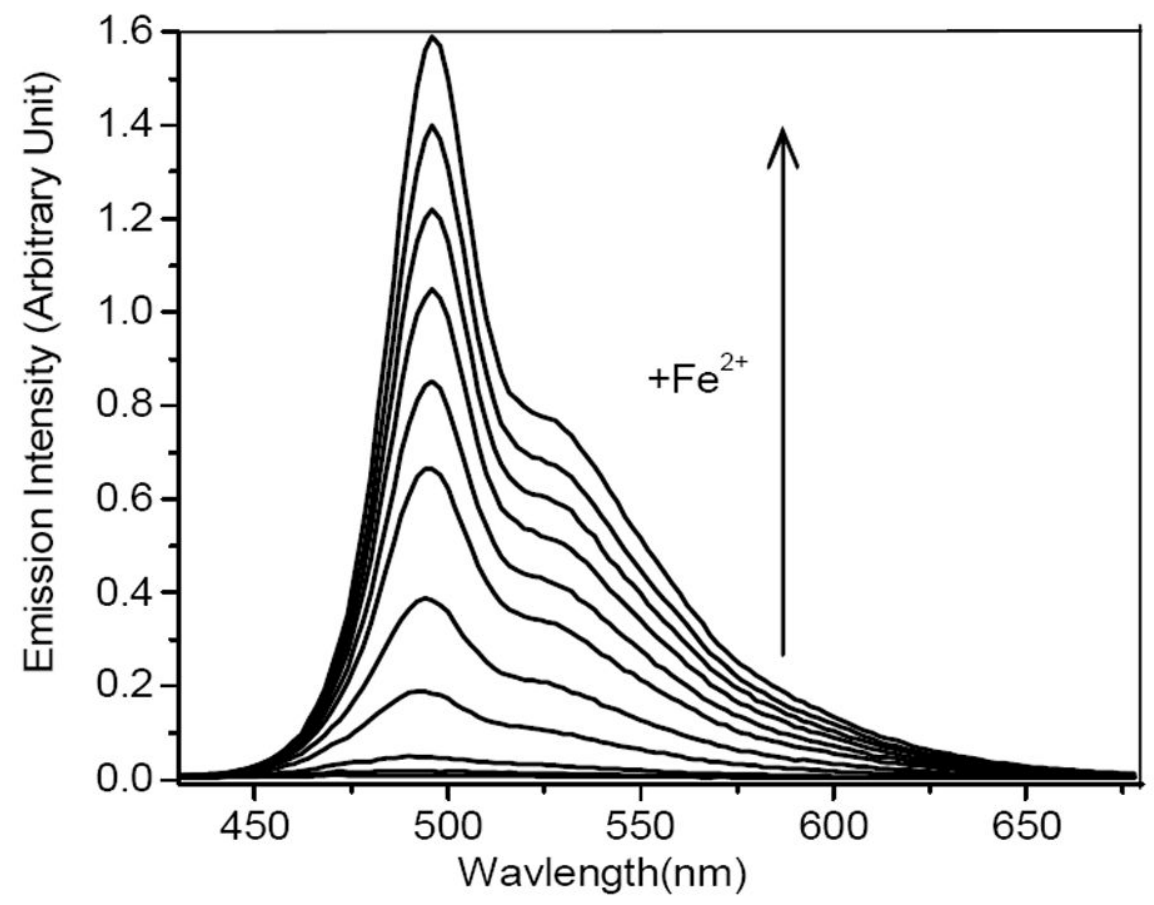

Figure 1.

Fluorescence response following excitation at $408 \mathrm{~nm}$ from tmeda-PPETE $/ \mathrm{Cu}^{2+}$ solutions upon addition of $\mathrm{Fe}^{2+}$ aqueous solution.; The concentrations of the $\mathrm{Fe}^{2+}$ for the spectra (from bottom to top) were $0,1,2,3,4,5,6,7,8,10 \mu \mathrm{M}$; The concentrations of tmeda-PPETE (with respect to the repeat unit) and $\mathrm{Cu}^{2+}$ were fixed at $5 \mu \mathrm{M}$. 


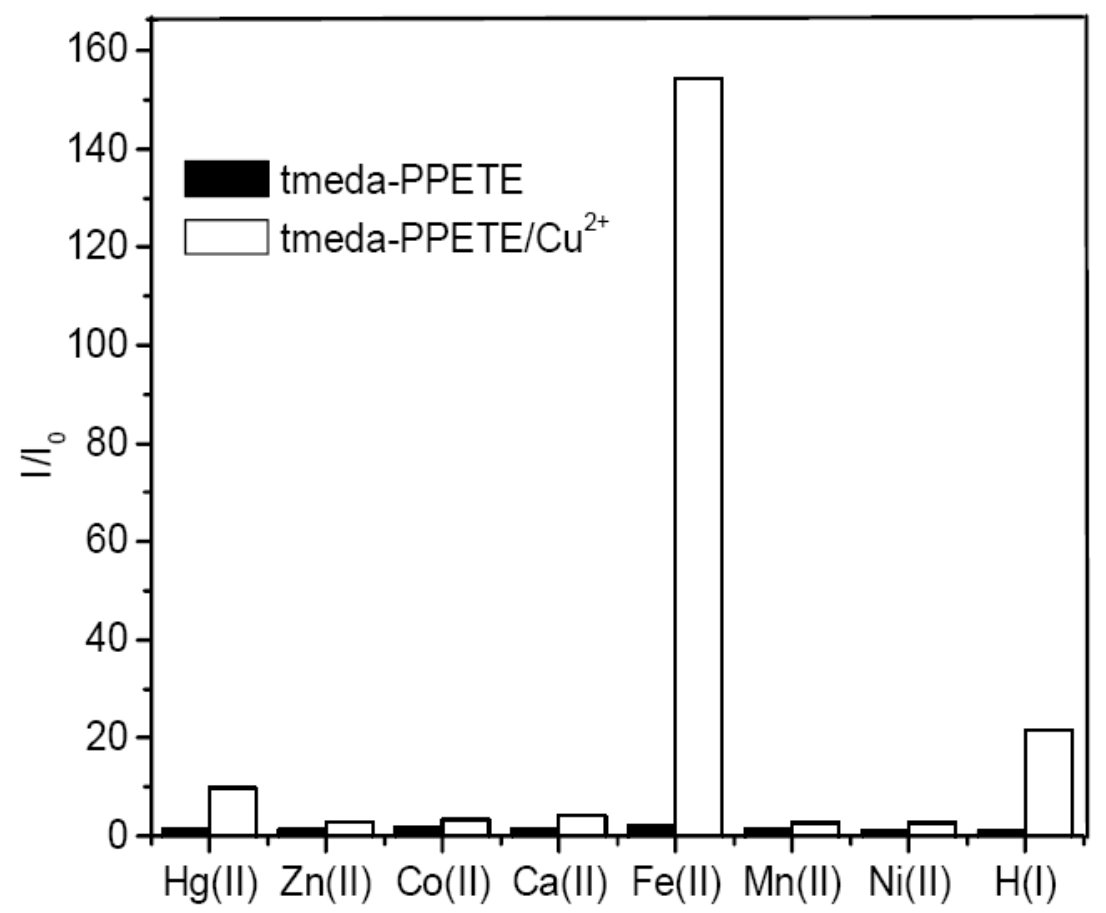

Figure 2.

Fluorescence response of tmeda-PPETE/ $\mathrm{Cu}^{2+}$ (white) or tmeda-PPETE (black) to various 10 $\mu \mathrm{M}$ cations in room temperature solution; The concentrations of tmeda-PPETE (with respect to the repeat unit) and $\mathrm{Cu}^{2+}$ were fixed at $5 \mu \mathrm{M}$. 